\title{
O PEQUENO PRÍNCIPE EM LIBRAS: UMA PROPOSTA DE CRÍTICA DE TRADUÇÃO
}

\author{
Ricardo Oliveira Barros ${ }^{1}$ \\ ${ }^{1}$ Universidade Federal de Santa Catarina, Florianópolis, Santa Catarina, Brasil \\ Marlova Aseff ${ }^{2}$ \\ ${ }^{2}$ Universidade de Brasília, Brasília, Distrito Federal, Brasil
}

Resumo: O presente trabalho discute as dificuldades e os possíveis caminhos ao construir a crítica da tradução de $O$ Pequeno Príncipe para a Libras realizada pelo projeto Acessibilidade em Bibliotecas Públicas (ABP) do governo federal brasileiro. Busca-se responder às seguintes perguntas: Que critérios podem ser seguidos para construir uma crítica de uma tradução para a língua de sinais? Que dificuldades estão envolvidas neste processo? Seguindo a perspectiva de análise reflexiva de Berman, se buscou desenvolver, por meio do escrutínio da tradução em questão e do cotejo entre ela e o seu original, ponderações que fossem mais do que somente uma atribuição de valor ao trabalho do tradutor. O processo de construção da crítica foi então observado a fim de inferir as dificuldades de criticar obras em Libras e que parâmetros podem funcionar como guia para a análise. Concluiu-se que o crítico enfrenta questões ligadas ao registro em vídeo e ao fato de o sistema literário da Libras ser ainda jovem. $\mathrm{E}$, ainda, que analisar a maneira como as traduções se alocam frente às demais obras em Libras é importante para que as discussões sobre esse polissistema literário se consolidem como área de estudo.

Palavras-chave: Crítica; Literatura em Libras; Tradução

\section{THE LITTLE PRINCE IN LIBRAS: A PROPOSAL FOR TRANSLATION CRITICISM}

Abstract: This work discusses the difficulties and the possible pathways to set a translation critic on The Little Prince translation into Libras car- 
ried out by the project Accessibility on Public Libraries from the Brazilian Federal Government. We sought to answer the following questions: Which criteria could be followed in order to discuss a translation critic concerning sign language? What are the difficulties involved in this process? According to Berman's perspective of reflexive analysis and considering the comparison and contrasting of the original work with its translation, we sought to develop considerations that concerned more than just an attribution of value to the translator's work. The process of constructing the critic was observed in order to infer the difficulties on how to discuss criticism on Libras works and that questions can also be a guide for the analysis. We have concluded that the critic faces issues when it comes to the register support of the work, and also that this is a young literary system. It is established that analyzing how the translations are allocated concerning other works in Libras is important so that the discussions about this literary polysystem can be solidified as a study area.

Keywords: Critics; Libras Literature; Translation

\section{Introdução}

O presente texto apresenta uma crítica de tradução da obra $O$ Pequeno Príncipe para a Libras. A edição analisada conta com recursos de acessibilidade, como legenda oculta, audiodescrição e janela de Libras. O olhar aqui se volta para a tradução para a língua de sinais, visando descrever a sua qualidade e de que maneira os aspectos linguísticos utilizados estão em conformidade com os demais elementos visuais da obra como um todo. Traz também reflexões sobre as dificuldades de se realizar uma crítica de tradução para a língua de sinais.

As críticas de tradução de obras em Libras são escassas, talvez porque poucas obras traduzidas para a Libras são comercializadas e, quando o são, não costumam suscitar críticas. Assim, este trabalho se propõe a ser mais um ponto de aproximação entre a área de estudos da tradução de línguas de sinais e a crítica de tradução. Buscamos responder às seguintes perguntas: Quais critérios podem ser seguidos para construir uma crítica de tradução para a língua de sinais e quais dificuldades estão envolvidas nesse processo?

Cad. Trad., Florianópolis, v. 41, $\mathrm{n}^{0}$ esp. 2, p. 19-39, ago/dez, 2021. 


\section{Sobre a noção de crítica}

A crítica aqui assume um sentido reflexivo, sendo uma forma de entender "a obra como o espaço discursivo em que inscreve um movimento crítico-reflexivo interessado no desenvolvimento de um pensamento a partir e através da obra" (Cardozo 234). A reflexão, neste caso, está na observação de fatores que podem ser relevantes para a construção da crítica da tradução em língua de sinais.

Ao refletir criticamente sobre uma tradução, o crítico deve estar ciente de que a sua ação reflete uma tomada de posição frente à obra e, portanto, tende a refletir um julgamento. Esse posicionamento é embasado pela sua crença ou concepção sobre o que é a tradução. Esse é um importante fator a ser considerado para a construção de uma crítica, pois o tradutor também parte de um ideal teórico sobre o que vem a ser o traduzir (Arrojo). Além disso, a crítica afetará a opinião do leitor em relação à obra (Cardozo), o que denota uma responsabilidade.

Primeiramente, a fim de garantir que a crítica aqui possua um cunho de reflexão, buscaremos entender de que maneira a tradução de $O$ Pequeno Príncipe para a Libras se insere dentro do sistema literário da língua de sinais no Brasil. Para isso recorremos à teoria dos polissistemas de Even-Zohar. Para o teórico, polissistema é um sistema múltiplo, ou seja, composto por diversos outros sistemas e que são parcialmente interligados e, ao mesmo tempo, integram um só sistema. Essa teoria permite entender as diferentes manifestações semióticas (pintura, literatura, música...) como partes de um todo (Even-Zohar).

Com esse pensamento, podemos entender de que forma as traduções de obras literárias interagem com as obras concebidas em determinado sistema literário. Para Even-Zohar, essa relação pode acontecer de duas formas: (i) pelo modo como as obras são selecionadas para serem traduzidas, e (ii) pela forma como as traduções adotam estratégias de adaptação às normas, hábitos e critérios específicos da cultura para a qual se traduz. Esse pensamento admite que a tradução faz parte de todos os polissistemas literários, consti- 
tuindo um sistema com funcionamento distinto da literatura nativa e se relacionando dinamicamente com ela.

Even-Zohar prevê que as traduções podem assumir um papel central dentro de um polissistema, cumprindo a função de suprir o que falta a ele por este ser jovem, por ser periférico ou por não produzir alguns gêneros apreciados pelos leitores. Ao crítico cabe ressaltar de que maneira uma tradução pode contribuir para a constituição da literatura da cultura receptora, e, para tanto, deve conhecer esse sistema. Portanto, é necessário conhecer como se constitui a literatura em Libras entre nós.

\section{A literatura em Libras}

A literatura em Libras integra a Literatura Surda, definida como a "produção de textos literários em sinais, que entende a surdez como presença de algo e não como falta, possibilitando outras representações de surdos, considerando-os como um grupo linguístico e cultural diferente" (Karnopp 102). Esse conceito tem sido discutido e aprofundado. Sutton-Spence, por exemplo, entende que esse conjunto literário pode incluir obras escritas na língua vocal -auditiva sobre os surdos, escritas por surdos em língua vocal-auditiva e produções em línguas de sinais, podendo ser produzidas por surdos e por ouvintes e versando sobre qualquer temática (no Brasil, essas últimas representam a literatura em Libras).

Mourão propõe uma classificação do polissistema da Literatura Surda em três grupos: tradução, adaptação e criação. Tradução refere-se às obras escritas em outras línguas e transportadas para o sistema literário da Libras. Adaptação diz respeito às obras traduzidas que sofrem uma intervenção no roteiro buscando aproximá-las à realidade cultural dos surdos. Criação inclui todas as obras que são compostas diretamente em Libras.

Considerando que a adaptação pode ser entendida como um tipo de tradução, é possível então separar a literatura em Libras entre as obras que são traduzidas para Libras e as que são diretamente 
produzidas nessa língua (Santos). Ao aplicar a teoria dos polissistemas ao caso da Libras e ao refletir sobre a maneira como esse se relaciona com o sistema da literatura e da cultura ouvinte do Brasil, Santos elaborou o seguinte esquema:

Figura 1 - Esquema de uma pequena parte do polissistema

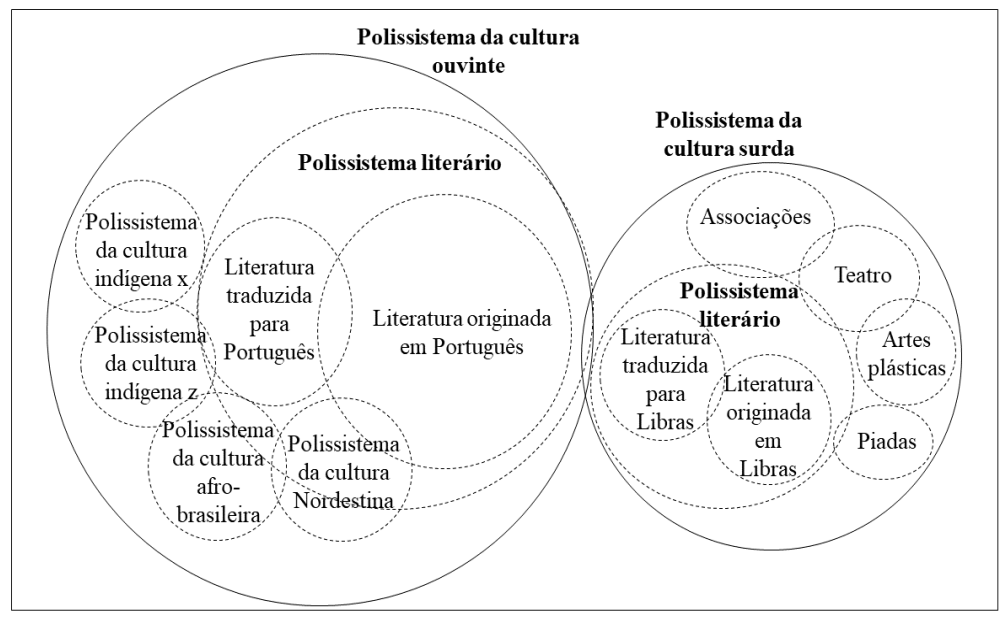

Fonte: Santos (106)

No esquema, é notório o tamanho do polissistema da cultura surda em relação ao polissistema da cultura ouvinte e, em consequência, a dimensão também menor do polissistema literário da Libras. Santos entende que "a literatura surda brasileira ainda não possui um acúmulo tão expressivo de poemas, poetas, leitores, tradutores, pesquisadores e estudiosos, e isso também dificulta as pesquisas e as reflexões sobre esse jovem sistema literário" (Santos 120). No entanto, pesquisas têm revelado que grande parte das produções de surdos são disponibilizadas na internet, principalmente em sites de armazenamento de vídeos, como o YouTube e o Vimeo, não sendo parte de um mercado editorial capitalizado, mas que nem por isso deve ser desconsiderado (Schallenberger). 
É fato, porém, que quando o acesso à internet de forma massiva ainda não era uma realidade nacional, o sistema literário da Libras recorreu às traduções de obras literárias. Com as mudanças no acesso às tecnologias de comunicação, o reconhecimento e estímulo ao uso da língua de sinais por meio de dispositivos legais como a Lei 10.436 de 2002, e o aprofundamento dos estudos sobre literatura surda no país, o polissistema se reconfigurou para dispensar um papel mais relevante às obras criadas em Libras. Isso, no entanto, não diminui a importância que as traduções assumem nesse polissistema.

Uma demonstração dessa importância é o mapeamento realizado por Damasceno e Damasceno, que reuniu obras publicadas por editoras no Brasil entre 2005 e 2015. Na pesquisa, constatou-se que a maior parte das obras publicadas eram traduções, num total de 15; a essas podemos acrescentar as adaptações, em número de oito produções, somando 23 obras de tradução frente a 14 obras de criação. Se considerarmos ainda que nessa última categoria, oito obras são autobiografias escritas em português, a diferença entre o que é traduzido para Libras e o que é produzido diretamente em Libras no mercado editorial brasileiro fica ainda maior. As obras de criação representariam somente $20,6 \%$ daquilo que compõe o polissistema literário da Libras no período pesquisado.

Os surdos já produzem literatura há tempos (Encrevé; Peixoto); e também os ouvintes que participam da comunidade surda traduzem literatura para a Libras. Mas foi somente com a possibilidade de registro de suas produções que o estudo das mesmas se viabilizou, sob os vieses cultural e linguístico, começando, assim, a definir essa literatura. Nesse sentido, Rose destaca a importância do registro em vídeo, visto que essa seria a melhor maneira de captar e gravar todas as especificidades da língua de sinais.

É verdade que há sistemas de escrita para as línguas sinalizadas que permitem registar no papel as suas nuances ${ }^{1}$, mas o meio mais

${ }^{1}$ O SignWriting é um desses sistemas de escrita, sendo o mais difundido. No levantamento de Damasceno e Damasceno, algumas obras de adaptação são escritas em português e em Libras escrita por meio desse sistema.

Cad. Trad., Florianópolis, v. 41, $\mathrm{n}^{0}$ esp. 2, p. 19-39, ago/dez, 2021. 
utilizado para isso continua sendo o vídeo. Isso se coaduna com o conceito de vários autores que consideram a literatura em língua de sinais como uma literatura do corpo e da performance (Klamt; Miglioli). Assim, o vídeo tem sido utilizado por tradutores autônomos e por instituições que contam com tradutores no seu quadro. Esse é o caso da obra que é o objeto da crítica neste trabalho. Tal fato também explicaria em parte a escassez de críticas de traduções para a Libras.

\section{Críticas de traduções para a Libras}

Até o momento, poucos trabalhos se debruçam sobre a construção de críticas de tradução para a Libras. Aqui, nos referiremos a dois estudos, o de Santos e o de Bentes, que em certo ponto tecem comentários que podem ser entendidos como críticas de tradução.

Santos, sob o título "No princípio era a palavra, mas a palavra foi traduzida para os sinais", aborda a tradução do livro bíblico Cântico dos Cânticos realizada pelo grupo religioso das Testemunhas de Jeová. O trabalho analisa os recursos utilizados para a criação de poeticidade no texto e a manutenção do registro e das metáforas do original. É visível que o autor realiza o cotejo entre original e tradução em trechos específicos e os compara ainda com traduções em outras línguas de sinais realizadas pelo mesmo grupo religioso. Como a tradução é em vídeo, utiliza fotografias dos instantes comentados e sobreposições de setas que buscam retratar os movimentos das mãos. A análise tem características de crítica, embora este não seja o objetivo primeiro do estudo.

Já o estudo de Bentes é uma dissertação de mestrado em Estudos da Tradução. A autora apresenta propostas de tradução para os trocadilhos de Alice no País das Maravilhas, tendo como base uma tradução para português e outra já realizada para a Libras. No segundo capítulo do trabalho, Bentes apresenta três outras traduções da obra para a Libras e tece comentários sobre elas com foco no seu objeto de pesquisa, os trocadilhos. 
Assim como Santos, Bentes recorre a fotografias da sinalização para realizar o cotejo entre original e tradução, e analisa a obra na totalidade. Com a experiência da análise, que em alguns momentos assume características de crítica, a autora chega a algumas constatações, dentre elas, nos chama a atenção as seguintes:

- Pouquíssimas pessoas têm se aventurado a traduzir literatura para surdos;

- Traduções da libras para o português são ainda mais escassas;

- O YouTube se estabelece como "vitrine" de apresentações culturais, pessoais e humorísticas dos surdos, espaço de produção, circulação e consumo de cultura;

- Os estudos que se dedicam à tradução de humor surdo têm em sua maioria as piadas como foco;

- A maioria das traduções foca simplesmente na mensagem geral do texto (quando não adaptadas à cultura surda);

- As traduções feitas por surdos são em sua maioria adaptadas à cultura surda;

- Não há uma normatização para a (apresentação visual) tradução (vídeo-gravada) desse tipo de produção;

- A tradução de humor (para a libras) se restringe em sua maioria a piadas e a algumas historietas infantis de cunho mais cômico;

- Omissões de elementos considerados mais "linguísticos" como jogos de palavras, expressões idiomáticas, entre outros, são comuns (Bentes 63- 64).

Os comentários da autora sobre as traduções oferecem vários possíveis caminhos que a crítica de tradução de obras para Libras pode seguir. E ainda revelam uma dificuldade para se analisar obras em Libras. Ao comentar sobre o escrutínio de uma tradução disponibilizada no formato de DVD, diz: "a tarefa é quase impossível (para este trabalho) de analisar todo o DVD” (Bentes 56). Ou seja, o cotejo de uma obra traduzida para Libras em vídeo com o 
seu original fica mais complicado, levando o crítico a recorrer às soluções apresentadas nos dois estudos acima.

Além disso, a presença da figura visível do tradutor no vídeo (ou de alguém que sinalize a tradução) também pode ser um problema. Esse sinalizante imprimirá ao texto não só o seu rosto, mas todas a peculiaridades corporais e de sinalização intrínsecos à sua persona, algo comparável ao timbre vocal, que é único de cada pessoa. Com isso se incorre no risco de criticar não a tradução, mas sim o tradutor, por tecer comentários sobre a sua sinalização e se esquivando de comentar os aspectos linguísticos ou o papel da tradução dentro do sistema literário; isso levaria a crítica para um nível muito raso.

Levando em conta todos os fatores comentados até aqui, partiremos agora para a explanação de como se construiu a nossa crítica e para a apresentação das reflexões que se desencadearam a partir da crítica da tradução de $O$ Pequeno Príncipe em Libras.

\section{Construindo a crítica}

Para construir esta crítica, seguiu-se os passos propostos por Berman, que iniciam com uma leitura da tradução e, em seguida, do original, permitindo, assim, que o crítico desenvolva suas primeiras impressões, que deverão guiar o trabalho da crítica. A isso se segue uma seleção de trechos considerados significativos, nos quais a obra se condensaria. Esses trechos escolhidos serão fundamentais para a análise. Berman também aconselha que se dê atenção ao tradutor, o que significaria entender qual é a sua posição em relação à tradução; qual o seu projeto ou seu objetivo ao traduzir; como ele se relaciona com as demais traduções da mesma obra e como a tradução criticada se situa em relação às demais.

$\mathrm{Na}$ análise são levados em conta aspectos da obra traduzida e cotejos entre original e tradução para que, a partir disso, "seja aberta uma série de questões, perspectivas, resumos” (Berman 86). No nosso caso, as reflexões desenvolvidas na crítica serão baseadas 
na questão do registro em vídeo e suas implicações, como a relação do texto em Libras com as imagens e legendas presentes na obra, e também nas questões linguísticas que explicitam as diferenças entre as duas culturas envolvidas. Atravessando todo o processo, é feita uma análise da recepção da tradução e, neste caso específico, de como ela é recebida dentro do sistema literário da Libras. E, finalmente, se faz o que Berman chama de "crítica construtiva", comentários que preparam o espaço para uma possível retradução, mas sem a intenção de prescrever um novo projeto.

Abaixo apresentamos o texto crítico sobre a tradução de $\mathrm{OPe}$ queno Príncipe em Libras e, em seguida, as discussões levantadas a partir dela.

\section{O Pequeno Príncipe em Libras}

O mundialmente famoso livro de Antoine Saint-Exupéry foi publicado pela primeira vez em 1943 nos Estados Unidos, com o título de Le Petit Prince. O livro conta as aventuras de um jovem príncipe narradas por um piloto que o conhecera durante um pouso de emergência no deserto do Saara. O livro já foi traduzido para mais de 200 línguas, ganhou várias adaptações para o teatro e duas para o cinema.

A obra é repleta de constatações feitas pelo principezinho sobre valores como a amizade e a forma como desenvolvemos laços uns com os outros. Não é difícil achar quem se lembre de frases como: "o essencial é invisível aos olhos, e só se pode ver com o coração"; ou: "tu te tornas eternamente responsável por aquilo que cativas". Os diálogos entre o adulto aviador e a criança majestade não escondem o tom de inocência do menino de outro planeta que estranhava muito a Terra. O jeito simples de dizer as coisas tornam a leitura agradável, e as frases de efeito como as citadas acima fazem sucesso entre os leitores que delas inferem metáforas.

No Brasil, a obra ganhou traduções para o português feitas por Mario Quintana (2017), Ferreira Gullar (2013), Ivone Benedetti 
(2015) e Frei Beto (2019), dentre outros. Mas a primeira delas foi do monge beneditino Dom Marcos Barbosa, uma versão que agora se considera consagrada. Foi lançada em 1954 pela editora AGIR e permaneceu sem alterações por 60 anos. Essa tradução foi o ponto de partida para a tradução para a Libras que é objeto deste texto. Trata-se, portanto, de uma retradução, ou tradução-pivô, e integra a edição acessível da obra.

A edição com recursos de acessibilidade está em formato de vídeo. A obra inteira conta com áudio do texto da tradução de Dom Marcos Barbosa, audiodescrição das aquarelas do original que aparecem na tela à medida que o texto é lido, legendas para pessoas surdas e ensurdecidas e tradução para a Libras.

A obra faz parte do projeto Acessibilidade em Bibliotecas Públicas (ABP), uma iniciativa do Sistema Nacional de Bibliotecas Públicas, do antigo Ministério da Cultura do Brasil, atual Secretaria Especial da Cultura. O projeto tem o objetivo de: "contribuir com a democratização do acesso às bibliotecas públicas e com a garantia dos direitos das pessoas com deficiência ao conhecimento e informação por meio de ações que favoreçam a equiparação de oportunidades" (ABP, 2019). Nesse projeto, o tradutor Félix de Oliveira participa da tradução de diversos livros de estilos diferentes, sendo também o intérprete. $\mathrm{O}$ tradutor também tem experiência com tradução de filmes do cinema nacional e interpretações no teatro.

A primeira questão que merece ser pensada sobre a obra relaciona-se ao seu formato de registro, o vídeo, fator que guarda relação com a receptividade da tradução. A obra tem o total de $2 \mathrm{~h} 01 \mathrm{~m} 20 \mathrm{~s}$, e nos tempos atuais, de volatilidade na comunicação, serão poucos - mesmo que utentes nativos da língua de sinais que se sentirão confortáveis em assistir por tanto tempo. Vídeos longos não tornam a "leitura" prazerosa (Ribeiro). Talvez fosse o caso de dividi-lo em vários segmentos menores conforme os capítulos do original ou, ainda, publicar uma edição em Libras escrita.

Outra questão que envolve o suporte é a necessidade de se pensar a composição visual como um todo. $\mathrm{O}$ vídeo permite a presença de recursos visuais que, trabalhando em conjunto com a Libras, 
podem contribuir para a construção da mensagem. É o caso de aproveitar inserções como a legenda para diminuir a quantidade de soletração manual, que complicam a recepção da sinalização. A exemplo disso, aos $01 \mathrm{~m} 30 \mathrm{~s}$ do vídeo, apresenta-se o nome do autor do original francês, e embora a legenda já mostre o nome escrito em português, o tradutor também o soletra em Libras (figura 02). Infelizmente, não parece ter ocorrido um trabalho em conjunto entre o tradutor e os demais profissionais envolvidos na produção do vídeo. Uma possibilidade eficiente seria que, em vez de soletrar manualmente, somente se apontasse para o espaço onde aparece a legenda.

Figura 2 - 01m 30s do vídeo da tradução quando o tradutor soletra o nome do autor do original

\section{OSequ}

Aurtor: Antotine de Salint Exxupêny

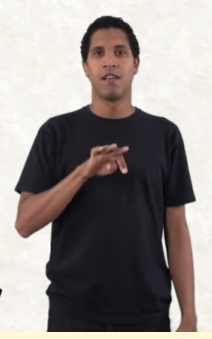

Fonte: ABP, 2016.

O mesmo princípio poderia ser usado nas estruturas de grande iconicidade. Cuxac e Sallandre explica que esse tipo de estrutura está relacionada com a capacidade que as línguas de sinais têm de reconstruir as experiências na "dimensão do 'assim' mostrando e/ ou imitando (como se fosse aquele de quem eu falo e quais as suas ações) resumidamente, a dimensão de trazer à vista pode sempre ser ativada”. Essa possibilidade de mostrar com as mãos pode ser

Cad. Trad., Florianópolis, v. 41, $\mathrm{n}^{0}$ esp. 2, p. 19-39, ago/dez, 2021. 
facilitada no caso das obras em vídeo que possuem recursos visuais de apoio (Albres et al.).

Um exemplo disso pode ser encontrado aos $02 \mathrm{~m} 21 \mathrm{~s}$. No trecho, o narrador do original recorda uma gravura que vira em um livro quando ainda era criança. No desenho, uma jiboia se enrolava no corpo de um animal e se preparava para engoli-lo. A aquarela aparece na tela com os animais em uma posição vertical com a jiboia enrolada no animal. Em dissonância, a estrutura utilizada pelo tradutor ao sinalizar representa a cobra engolindo o animal, sem se enrolar nele e na horizontal (figura 03). O ideal seria uma sinalização que reproduzisse a ação mostrada no desenho, ou que a utilizasse como complemento.

Figura 3 - 02m21s o tradutor utiliza uma estrutura de grande iconicidade que destoa da gravura aparente na tela

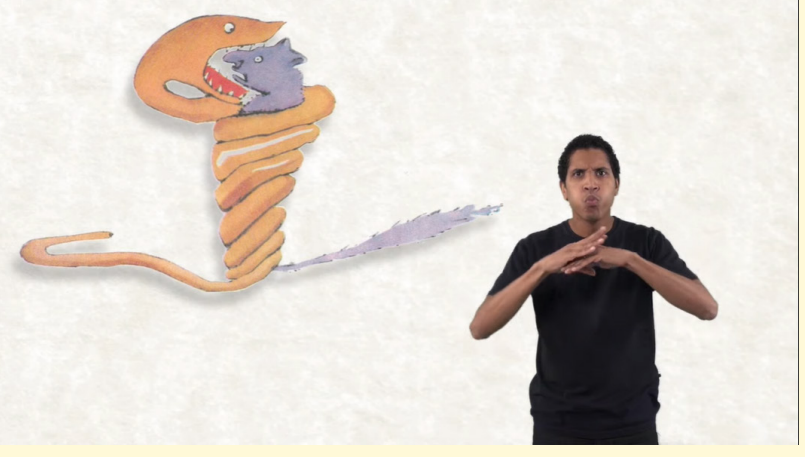

Fonte: ABP, 2016

O mesmo acontece nos momentos em que o tradutor assume o lugar de um dos personagens. Na Libras, ao sinalizar diálogos, o sinalizante pode assumir o lugar de um dos personagens ao virar o corpo para um dos lados. Com isso, se estabelece um espaço para cada personagem, sendo desnecessária a explicitação de quem está 
falando (Quadros; Karnopp). O espaço de cada personagem pode (deve, por questão de harmonia) seguir o que já está estabelecido na imagem. Em alguns momentos, isso não ocorre, como no diálogo entre o principezinho e a rosa em seu asteroide (a partir dos $37 \mathrm{~min}$ ). Seria mais harmonioso se o intérprete emitisse a fala de cada personagem se posicionando ao mesmo lado em que aparecem na aquarela.

Outras questões dizem respeito somente à tradução realizada, independentemente dos demais elementos que compõem a edição acessível. A primeira tem a ver com a tradução do da frase mais memorável do livro: "tu te tornas eternamente responsável por aquilo que cativas", dita pelo príncipe para a raposa. No original, em francês o verbo é "apprivoiser", que tem o sentido de domesticar, domar, e que foi traduzido por cativar. Bottmann, uma das tradutoras do livro para o português, comenta que "apprivoiser pouco ou nada tem a ver com 'cativar', não tem a acepção de prender em cativeiro e, sobretudo, não tem a acepção de encantar, conquistar, seduzir que há em 'cativar'” (Cruvinel 2). Porém, a tradução de Dom Marcos Barbosa já se consagrou, o que torna difícil que qualquer novo tradutor a modifique.

Em Libras, por outro lado, não há uma versão clássica consagrada. A obra inteira tinha acabado de chegar a esse novo sistema literário. ${ }^{2}$ Isso representaria uma oportunidade de criação e liberdade na tradução, visto que sobre as costas do tradutor não recai o peso de uma forma cristalizada. Assim, ter a consciência dos problemas que outros tradutores já enfrentaram, permitiria realizar uma correção da versão portuguesa quando versada em Libras, mesmo sendo ela uma tradução-pivô, que parte do português. Nesse caso, o tradutor optou pelo sinal CARINHO (figura 04).

\footnotetext{
${ }^{2}$ No mesmo ano foi publicada uma versão em Libras pela editora Arara Azul, traduzida por Janine Soares e Marcos Marquioto. A versão da ABP foi postada no Youtube em outubro de 2016, a versão da Arara Azul não informa o mês em que a edição ficou disponível, somente o ano.
}

Cad. Trad., Florianópolis, v. 41, no esp. 2, p. 19-39, ago/dez, 2021. 
Figura 4 - Sinal CARINHO traduzindo "cativar"
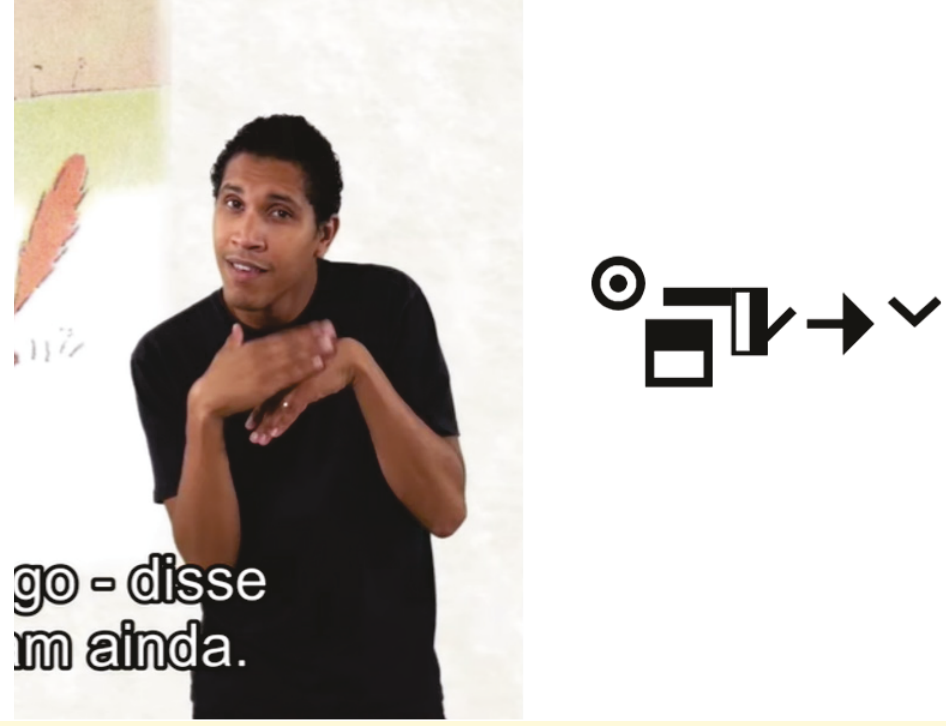

Fonte: ABP, 2016

No próprio contexto do diálogo entre o principezinho e a rapo$\mathrm{sa}$, se explica o sentido que o autor quis dar ao verbo. Ao ser questionada sobre o significado de "cativar", a raposa esclarece que significa "criar laços", que é traduzido por UNIR e RECÍPROCO (figura 05). Assim, a tradução de "cativar" como CARINHO é condizente com a ideia geral da palavra no livro, e ainda assim mantém certo grau de relação com o significado de "apprivoiser", já que o sinal pode ser entendido como acariciar, lembrando a forma como o dono alisa a cabeça do seu animal domesticado ou em processo de domesticação. 
Figura 5 - UNIR e RECIPROCIDADE traduzindo "criar laços"
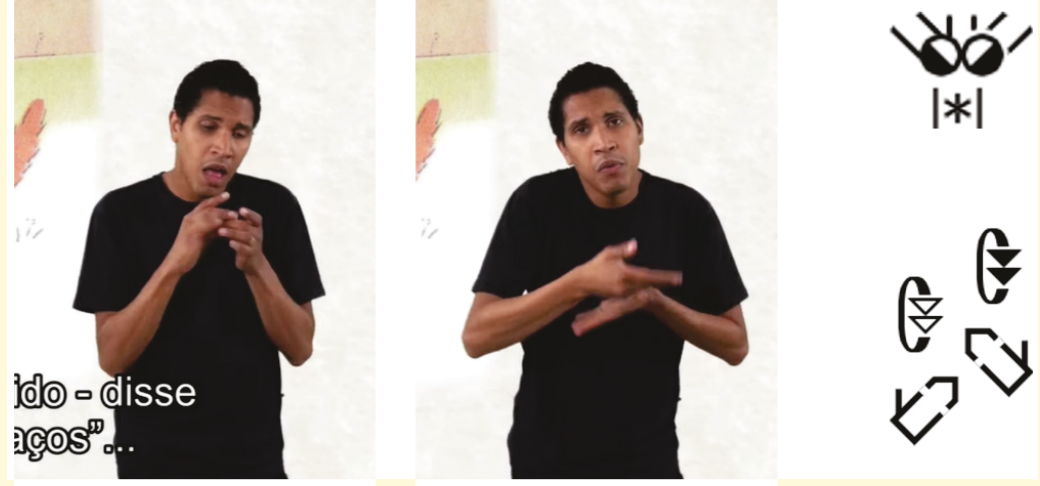

Fonte: ABP, 2016

A mesma oportunidade de correção está relacionada aos sistemas culturais envolvidos. Por exemplo, em francês, a raposa (le renard) é um personagem masculino por ser assim designado no sistema daquela língua; já em português, é feminino. Em Libras, não há gênero designado por meio de desinência ou artigo, mas somente pela junção do sinal de HOMEM/MACHO ou MULHER/ FÊMEA que não é necessariamente obrigatório; o sexo de uma pessoa ou animal pode permanecer indefinido, que é o caso aqui. $\mathrm{O}$ tradutor utiliza somente o sinal RAPOS@ $@^{3}$ para o personagem, sem defini-lo macho ou fêmea; mas ao incorporar o personagem para pronunciar as suas falas, os trejeitos que ele executa são femininos, comprometendo a indefinição.

Tais comparações nos levam a perceber que a tradução em questão deixa escapar algumas oportunidades de reaproximação dos sentidos do original com a cultura brasileira (surda). Mas também nos permitem concluir que isso se dá devido ao abeiramento da versão em Libras à tradução em português da qual parte. Além disso, parece que o tradutor não consultou o original em francês,

${ }^{3}$ O símbolo @ foi inserido aqui para manter a indefinição do gênero, como existe no sinal em Libras.

Cad. Trad., Florianópolis, v. 41, n⿳0 esp. 2, p. 19-39, ago/dez, 2021. 
foi uma metatradução ou tradução-pivô. A importância da edição com recursos de acessibilidade é inegável. Contudo, é difícil que o tradutor se desprenda da tradução consagrada e goze da sua liberdade tradutória, uma vez que ele parte dela para retraduzir. Além de cumprir bem o objetivo do projeto, de promover a democratização do acesso às bibliotecas públicas, a obra se insere no polissistema literário da Libras contribuindo para a ampliação do repertório de gêneros nessa língua.

\section{Conclusão}

Este artigo trouxe reflexões sobre algumas questões que podem surgir ao se avaliar uma tradução para a língua de sinais e apresentou a crítica da tradução para Libras de $O$ Pequeno Príncipe realizada pelo projeto ABP, do governo federal do Brasil. A tradução integra o polissistema literário da Libras e cumpre o importante papel de prover o que falta para essa cultura, além de incentivar e subsidiar os produtores de literatura a também criarem obras do mesmo gênero diretamente na língua sinalizada.

Viu-se que a crítica de tradução no polissistema da Libras é incipiente. Isso pode se dar pelo fato de configurar um sistema literário jovem, que ainda produziu e traduziu relativamente pouco. Ou, ainda, devido ao suporte de registro das obras, na sua maioria em vídeo, o que complica o cotejo das traduções com o original e mesmo a sua leitura. Outro fator a ser observado é a presença corpórea do tradutor, o que dá um rosto à tradução e pode resultar com que a crítica se volte à performance da pessoa e não à tradução propriamente.

A crítica construída ateve-se a discutir questões de composição visual da obra, entendendo as imagens, legendas do vídeo e a Libras como complementares, o que deveria influenciar a tradução. Além disso, considerou questões tradutórias que são implicações da forma como se traduziu: uma metatradução. Essa forma dá liberdade ao tradutor de voltar ao "primeiro original" em francês 
e fazer escolhas que fogem dos problemas que já verificados na tradução desse livro para o português.

Para escrever esta crítica, foi necessário recorrer a fotografias da tradução para apresentar comentários sobre a obra como cotejo, apesar das limitações desse meio. Percebemos que o uso da língua de sinais escrita pode ser um ótimo recurso esclarecedor da sinalização, visto que ali há a indicação dos movimentos que inexistem na fotografia. Talvez fosse o caso pensar na possibilidade de que a crítica seja produzida no mesmo suporte que a obra, o vídeo. Mas isso representaria uma demanda de conhecimentos e recursos que a tornariam igualmente trabalhosa.

Ao longo desta análise, percebemos que mais do que o cotejo entre original, tradução e comentários sobre aspectos linguísticos que representam os problemas da tradução, é importante refletir sobre o papel das obras dentro do polissistema literário da Libras. Assim, contribui-se para o fortalecimento das discussões sobre essa literatura.

\section{Referências}

ABP - Acessibilidade em Bibliotecas Públicas. "O Pequeno Príncipe com recursos de acessibilidade". Youtube, 04/10/2016. Web. 20/11/2019. https:// www. youtube $. \operatorname{com} /$ watch? $v=$ foMiwFlVHCc\&t $=761 \mathrm{~s}$.

Albres, Neiva de Aquino; Mairla Pereira Pires Costa; Harisson Geroto Adams. "Contar um conto com encantamento: a construção de sentidos e efeitos da tradução para libras". Revista Diálogos (RevDia), Dossiê temático "Educação, Inclusão e Libras”, 6.1, Jan-Abr (2018). 15/11/2019. https://periodicoscientificos.ufmt.br/ ojs/index.php/revdia/article/view/6316/pdf.

Cad. Trad., Florianópolis, v. 41, $\mathrm{n}^{0}$ esp. 2, p. 19-39, ago/dez, 2021. 
Arrojo, Rosemary. "A que são fiéis tradutores e críticos de tradução? Paulo Vizioli e Nelson Ascher discutem John Donne”. In: Tradução, desconstrução e Psicanálise. Rio de Janeiro: Imago, 1993, p.15-26. Impresso.

Benedetti, Ivone. "O pequeno príncipe, três notas de uma tradutora". Ivone Benedetti, 2015. 20/11/2019. www.ivonecbenedetti.com.br/pequeno-principenotas-de-tradutora .

Bentes, Thaisy. "A tradução de trocadilhos em Alice no país das maravilhas para a Língua Brasileira de Sinais - LIBRAS”. Dissertação Universidade de Brasília, 2018.

Berman, Antoine. Pour une critique des traductions: John Donne. Paris: Éditions Gallimard, 1995. Impresso.

Bottmann, Denise. "As traduções brasileiras de pequeno príncipe. Traduzindo o pequeno príncipe”, 2015. 20/11/2019. www.traduzindoopequenoprincipe. blogspot.com/2015/02/as-traducoes-brasileiras-do-pequeno.html.

BRASIL. "Acessibilidade em bibliotecas públicas". Acessibilidade em bibliotecas públicas. Web. 20/11/2019. www.acessibilidadeembibliotecas.culturadigital.br/ sobre-o-projeto/.

Cardozo, Mauricio Mendonça. "Tradução \& os sentidos da crítica". In Tradução \&: perspectivas teóricas e práticas Lauro Maia Amorin.; Cristina Carneiro Rodrigues, Érica Nogueira de Andrade Stupiello (Orgs) São Paulo: Editora UNESP; São Paulo: Cultura Acadêmica, 2015, pp. 233-262.

Cruvinel, Gilberto. "Traduzindo o Pequeno Príncipe, por Denise Bottmann". Jornal GGN. 24/08/2015. Web. 20/11/2019. https://jornalggn.com.br/literatura/ traduzindo-o-pequeno-principe/.

Cuxac, Christian; Marie Anne Sallandre. "Iconicity and arbitrariness in French Sign Language: Highly iconic structures, degenerated iconicity and diagrammatic iconicity". In Verbal and signed languages: Comparing structure, constructs and methodologies. Elena Pizzuto, Paola Pietrandrea, Raffaele Simone (Orgs.). Berlin: de Gruyter, 2008. p.13-33. 
Damasceno, Eduardo Filgueiras; Tatiane Valau Pereira Damasceno. "Mapeamento sistemático da literatura surda". Náu literária. 14.1 (2018): 216-229. Periódicos científicos da UFRGS. 16/11/2019. https://seer.ufrgs.br/NauLiteraria/article/ view/84338/48675.

Encrevé, Florence. "A família dos surdos-mudos face à ideia do progresso no século XIX”. Tradução de Rosemeri Bernieri de Souza. Moara. 51 (2019):261282. Periódicos UFPA. 15/10/2019. https://www.periodicos.ufpa.br/index.php/ moara/article/view/7347.

Even-Zohar, Itamar. "La posición de la literatura traducida en el polisistema literario". Traducción de Montserrat Iglesias Santos revisada por el autor. En Teoría de los Polisistemas, Estudio introductorio, compilación de textos y bibliografía por Montserrat Iglesias Santos. [Bibliotheca Philologica, Serie Lecturas] Madrid: Arco, pp. 223-231, 1999.

Karnopp, Lodenir Becker. "Literatura Surda". Educação Temática Digital. 7.2 (2006):98-109. Portal de periódicos eltrônicos científicos da Unicamp. 27/09/2019. https://periodicos.sbu.unicamp.br/ojs/index.php/etd/article/view/795.

Klamt, Marilyn Mafra. "Visual sonority in Brazilian Sign Language literature". Revista Brasileira de Linguística Aplicada. 17.2 (2017): 277-305. Scielo. 16/10/2019. https://www.scielo.br/pdf/rbla/2017nahead/1984-6398rbla-201710561.pdf.

Miglioli, Sarah. "Análise da poesia em língua de sinais sob a perspectiva semiótica”. Signo 43.78 Set-Dez (2018): 44-54. Universidade de Santa Cruz do Sul. 16/10/2019. https://online.unisc.br/seer/index.php/signo/article/ download/11791/pdf.

Mourão, Carlos Henrique Nunes. "Literatura Surda: produções culturais de surdos em língua de sinais". Dissertação Universidade Federal do Rio Grande do Sul, 2011.

Peixoto, Janaina Aguiar. "O registro da beleza nas mãos: a tradição de produções poéticas em língua de sinais no Brasil”. Tese Universidade Federal da Paraíba, 2016. 
Quadros, Ronice Muller de; Lodenir Becker Karnopp. "Língua de sinais brasileira: estudos lingüísticos”. Porto Alegre; ArtMed, 2004. Impresso.

Ribeiro, Arenilson Costa. "Literatura de Cordel contemporânea: uma tradução prazerosa do par linguístico Português Libras”. Dissertação Universidade Federal de Santa Catarina, 2020.

Rose, Heidi. "A critical methodology for analyzing American Sign Language literature”. Dissertation Arizona State University, 1992.

Saint-Exupéry, A. “O pequeno príncipe”. Tradução de Dom Marcos Barbosa. Rio de Janeiro: Agir, 1999.

Santos, Emerson Cristian Pereira dos. "No princípio era a palavra, mas a palavra foi traduzida para os sinais”. Cadernos de Tradução. 38.3 Set-Dez (2018): 93124. Portal de periódicos UFSC. 30/11/2019. https://periodicos.ufsc.br/index. php/traducao/article/view/2175-7968.2018v38n3p93.

Schallenberger, Augusto. "Ciberhumor nas comunidades surdas". Dissertação Universidade Federal do Rio Grande do Sul, 2010.

Ricardo Oliveira Barros. E-mail: ricardo.oliveira.barros@live.com. https://orcid. org/0000-0002-4600-2744.

Marlova Aseff. E-mail: marlova.aseff@gmail.com. https://orcid.org/0000-00016188-3386.

Cad. Trad., Florianópolis, v. 41, no esp. 2, p. 19-39, ago/dez, 2021. 